\title{
Hospitalisation with otitis media in early childhood and cognitive function in young adult life: a prevalence study among Danish conscripts
}

Marie Mortensen ${ }^{1 *}$, Rikke Beck Nielsen ${ }^{1 \dagger}$, Niels Fisker $^{2+}$ and Mette Nørgaard ${ }^{1+}$

\begin{abstract}
Background: Otitis media $(\mathrm{OM})$ is a very common condition in children and occurs during years that are critical to the development of learning, literacy, and math skills. Therefore, among a large cohort of Danish conscripts, we aimed to examine the association between hospitalisation with $\mathrm{OM}$ in early childhood and cognitive function and educational level in early adulthood.

Methods: We conducted a population-based prevalence study using linked data from healthcare databases and conscription records of Danish men born between 1977 and 1983. We identified all hospitalisations with OM before 8 years of age. Cognitive function was measured by the Boerge Prien validated group intelligence test (Danish Børge Prien Prøve, BPP). We adjusted for potential confounders with and without stratification by hearing impairment. Furthermore, we examined the association between hospitalisation with $\mathrm{OM}$ and the prevalence of having achieved a General Certificate of Secondary Education (GCSE), stratified by quartiles of BPP scores.
\end{abstract}

Results: Of the 18412 eligible conscripts aged 18-25 years, 1000 (5.5\%) had been hospitalised with OM before age 8. Compared with conscripts without such a record, the adjusted prevalence ratio (PR) for a BPP score in the bottom quartile was 1.20 (95\% confidence interval [Cl]: 1.09-1.33). There was no major difference in the proportion of men with a GCSE and those without among those hospitalised with OM in early childhood. For men in the bottom and upper quartiles of BPP scores, the PRs for early childhood hospitalisation with OM were 0.89 (95\% Cl: 0.59-1.33) and $0.96(95 \% \mathrm{Cl}, 0.88-1.05)$, respectively. Among men with severe hearing impairment, the proportion with a BPP score in the bottom quartile did not differ between those with and without an OM hospitalisation $[\mathrm{PR}=1.01$ (95\% Cl: 0.78-1.34)].

Conclusions: Overall, we found that hospitalisation with OM in early childhood was associated with a slightly lower cognitive function in early adulthood. Hospitalisation for OM did not seem to influence the prevalence of GSCE when level of BPP was taken into account.

Keywords: Otitis media, Cognitive function, Educational level, Hearing impairment

\section{Background}

Acute otitis media (OM) is the most common infectious disease in young children, having occurred in $80 \%$ of all children by age 3 [1]. Furthermore, acute $\mathrm{OM}$ and $\mathrm{OM}$ with effusion (OME) are among the main reasons for early childhood consultations with general practitioners,

\footnotetext{
* Correspondence: mm@dce.au.dk

${ }^{\dagger}$ Equal contributors

'Department of Clinical Epidemiology, Aarhus University Hospital, Olof Palmes Allé 43-45, 8200, Aarhus N, Denmark

Full list of author information is available at the end of the article
}

and acute $\mathrm{OM}$ is one of the most common reasons for prescribing antibiotic treatment $[2,3]$.

Since OM occurs in the critical years of language, literacy, and math skill development [4], OM in early childhood may affect cognitive function later in life. In a literature review of Monasta et al., permanent hearing impairment was found to be a possible effect of OM in developing countries [5]. In a longitudinal cohort study of 74 children with early OM, Gravel et al. also found that mild conductive hearing impairment may influence auditory abilities in the longer term but only at high-

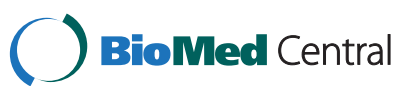


frequency thresholds [6]. Moreover, in a prospective cohort study of 73 children with congenital deafness, Coletti et al. demonstrated improved auditory, speech language, and cognitive performances in children who received a cochlear implant prior to 12 months of age compared with children implanted later [7]. Children with mild to moderate permanent hearing loss are at risk for later effects on language and academic development [8]. In a meta-analysis Roberts et al. found no to very small effect of OM to speech and language development in most children [9]. These findings imply an association between hearing impairment and cognitive function.

However, the long-term consequences of OM are inadequately understood, and data on the association between OM in early childhood and cognitive function in adulthood are sparse and contradictory. For instance, Bennett et al. followed a birth cohort of 1000 children into their teens and found that a history of early middle ear disease appeared to affect reading ability, verbal intelligence quotient, and behavior problems [10]. In contrast, Zumach et al. found in a cohort study of 65 children that OM in early childhood was associated with hearing impairment, which decreased language comprehension and language skills at age 2, but not at age 7 [11]. Similarly, Grievink et al. found no correlation between the effects of OME and linguistic ability at age 7 in a cohort of 305 children [12]. In addition, the prospective study of 698 children by Johnson et al. found that prolonged OME was associated with decreased cognitive function at age 3 , but that this association was not found by ages 5-7 [13]. Finally, in a prospective study of 241 children at 3 years of age, Paradise et al. found no correlation between the duration of OME and verbal aspects of cognition [14].

As cognitive function has been examined predominantly in early childhood and with school-age children, whether or not OM in early childhood and its possible impact on cognitive function also affects the level of education achieved is also not fully clarified [10-14]. Along these lines, a previous study by Welch and Dawes found no association between early childhood middle ear disease and adult measures of education [15].

Therefore, we examined the association between hospitalisation with $\mathrm{OM}$ in early childhood and cognitive function and educational level in young adult life using a large Danish army conscript data registry.

\section{Methods}

We conducted a prevalence study based on registry data collected in the Fifth Military Conscription District of Denmark, which includes the former counties of North Jutland and Viborg (population approximately 700 000). We included all men born as singletons from January 1, 1977, to December 31, 1983, who registered in the Fifth Military Conscription District from 1997 to 2003. Evaluation at the military draft board is mandatory for all Danish men aged 18-20 years. Men must register with authorities in one of the country's conscription districts, which were determined by their place of residence at age 18. During registration, men can report conditions that potentially preclude military service. Draft board physicians verify these reports and men with a verified condition are exempted from military duty without further examination. Documentation for the diagnosis leading to exemption is filed in the Conscript Registry and coded according to the 10th revision of the International Classification of Diseases (ICD-10) [16].

\section{Otitis media}

We used the civil registration number (a unique personal identifier assigned at birth) to link data from the Conscript Registry to information on previous hospitalisations for OM recorded in the Danish National Registry of Patients (DNRP) [17]. The DNRP contains data on all hospitalisations in Denmark since 1977, including civil registration numbers and diagnoses coded according to the International Classification of Diseases eighth revision (ICD-8) until 1994, and the tenth revision thereafter [16].

We defined hospitalisation with $\mathrm{OM}$ as at least one hospital diagnosis of OM (ICD-8 codes 381 and 382) registered before the age of 8 , since the prevalence of OM among Danish children is highest in this age group [18]. Thus, we included cases of OM with and without mastoiditis, acute OM, OME, and chronic suppurative OM. Hereafter, OM refers to any of these different types of OM.

\section{Cognitive function and educational level}

All men who attend the evaluation at their military draft board must take a 45-minute group intelligence test, the Boerge Prien test (Danish Børge Prien Prøve, BPP), which has been used since 1957 by Danish military draft boards [19]. The test includes four time-limited subtests: letter matrices, verbal analogies, number series, and geometric figures. The single final score is the sum of correctly answered items (range: 0-78). BPP scores correlate to a large extent with scores in the Wechsler Adult Intelligence Scale (WAIS) (correlation coefficient $=0.82$ ), although the $\mathrm{BPP}$ is a group test and the WAIS is an individuallyadministered test. Nevertheless, both tests are assumed to measure general intelligence [19]. From the conscript records, we also obtained information on whether the conscripts had achieved or were currently achieving the General Certificate of Secondary Education (GCSE), which is typically achieved at the age of 18 or 19 in Denmark.

\section{Covariates}

We obtained information on gestational factors from the Danish Medical Birth Registry, which has tracked all 
births in Denmark since January 1, 1973 [20]. The information is derived from birth notification forms completed by midwives attending the birth. Variables include civil registration number, date and place of birth, gestational age, birth weight, maternal parity, and, since 1978, information on maternal marital status and Apgar score.

Given that permanent hearing impairment may be a consequence of $\mathrm{OM}$ in developing countries [5] and hearing impairment is also associated with cognitive function $[7,8]$, we obtained information on hearing from conscript records. At the conscript examination an audiometric test is performed. The recording of the audiogram measurements are undertaken at frequencies 500, 1000, 2000, 3000, 4000, 6000 and $8000 \mathrm{~Hz}$. Initial screening are carried out equivalent to 20 decibel [21]. Hearing is classified on a scale from $0-5$ (severe hearing impairment to no hearing impairment). To improve the precision of the estimates, we collapsed the scale into severe hearing impairment $(0-3)$, moderate hearing impairment (4), and no hearing impairment (5).

\section{Statistical analysis}

We first constructed a box-and-whisker plot of BPP score distributions according to age at first hospitalisation for OM. We defined low cognitive function as a BPP score in the bottom quartile and used a logbinomial regression to estimate crude and adjusted prevalence ratios (PRs) for a BPP score in this quartile, according to age at first hospitalisation for OM [22]. PRs for a BPP score in the bottom quartile were estimated and stratified according to hearing impairment measured at the time of conscription examination.

The following possible confounding factors were included as identified from the literature: birth order $(0,1$, $2,3+)$, maternal age $(\leq 20,21-35,>35$ years $)$, marital status (married/unmarried), 5-minute Apgar score $(<7,7-10)$, gestational age, a composite variable derived from gestational age and birth weight [small for gestational age (SGA) or not] [23], and hearing score at conscription (severe, moderate, or no hearing impairment). In the regression analysis all variables were entered as sets of indicator variables. In a separate analysis we additionally adjusted for a previous diagnosis of febrile seizures or epilepsy. We examined PRs for OM hospitalisation and GCSE stratified into four quartiles by BPP score. To avoid loss of observations, missing values were estimated using multiple imputations, such that five imputed datasets were created and analysed with their averages serving as the estimates $[24,25]$. The regression model used for imputation included variables for gestational age, SGA or non-SGA, birth order, maternal age, marital status, and Apgar score 5-minutes after birth [26]. Confidence intervals (CI) around these estimates reflect uncertainty both about the value of the PRs and about the imputed values.
There was a lack of cognitive data on the exempted men because many of the conscripts $(11.9 \%)$ were exempted from draft board examination. To quantify this potential selection bias, a sensitivity analysis was performed in which the regression analyses were repeated with imputation of BPP scores for all the 2470 exempted men. To assess the maximal impact of a potential selection bias, the regression analyses for the worst case scenario and best case scenario was repeated assuming that all exempt men had a BPP score in the bottom quartile and no exempt men had a BPP in the bottom quartile, respectively. Model-estimated PRs were compared with corresponding pooled MantelHaenszel (non-parametric) estimates. In an additional analysis, all men with a previous diagnosis of meningitis were excluded (68 men out of 18412 in the study population).

Data were analysed using Stata software, version 11.2 (Stata, 4905 Texas, USA).

The study was approved by the Danish Data Protection Agency (http://www.datatilsynet.dk/english/, record no. 2011-41-5807). Data were obtained from the Conscript Registry, Danish Medical Birth Registry, and the DNRP. According to Danish legislation the study did not require permission from a Scientific Ethical Committee.

\section{Results \\ Descriptive data}

A total of 21051 men born as singletons during the 1978-1983 period were registered in the Fifth Conscription District of Denmark. Of these, $161(0.8 \%)$ had been hospitalised with $\mathrm{OM}$ after the age of 8 . Of the eligible men, 2470 (11.7\%) were exempt from draft board evaluation for health reasons. BPP scores were missing for 8 of the 18420 non-exempt men (0.04\%), leaving 18412 men in the analysis (descriptive data are presented in Table 1). Of these, 1000 men (5.4\%) had been hospitalised with OM before age 8 .

The prevalence of exemption prior to draft board evaluation was $20 \%$ for men hospitalised with OM in early childhood and $11 \%$ for men with no record of a hospitalisation with OM.

For the non-exempt conscripts, the median BPP scores were 42 (interquartile range: 35-48) for men with an OM hospitalisation and 44 (interquartile range: 38-50) for men without an OM hospitalisation (Table 1). Most cases of hospitalisation with OM (37\%) occurred in the second year of life. The median BPP scores varied between 41 and 44 (see Figure 1) when stratified according to age at first hospitalisation with OM.

\section{Prevalence ratios for Boerge Prien test (BPP) scores}

The prevalences of BPP scores in the bottom quartile (score $\leq 37)$ were $31.2 \%(312 / 1000)$ for men hospitalised with OM in early childhood and $25.1 \%(4370 / 17412)$ for men without such a hospitalisation. 
Table 1 Characteristics of conscripts, who were evaluated at the draft board and had a Boerge Prien test (BPP)

\begin{tabular}{|c|c|c|c|}
\hline \multirow[b]{2}{*}{ Variables } & \multicolumn{3}{|c|}{ Otitis media hospitalisation in childhood } \\
\hline & Yes & No & Total \\
\hline Men evaluated by the draft board, $\mathrm{n}(\%)$ & $1000(5.4 \%)$ & $17412(94.6 \%)$ & $18412(100 \%)$ \\
\hline BPP score, median (interquartile range) & $42(35-48)$ & $44(38-50)$ & $44(38-50)$ \\
\hline Proportion with a BPP score in the bottom quartile (\%) & $312(31.2 \%)$ & $4370(25.1 \%)$ & $4682(25.4 \%)$ \\
\hline Birth weight in grams, median (interquartile range) & $3450(3125-3760)$ & $3510(3160-3875)$ & $3500(3150-3875)$ \\
\hline \multicolumn{4}{|l|}{ Gestational age, no. (\%) } \\
\hline Preterm (<37 weeks) & $53(5.3 \%)$ & $648(3.7 \%)$ & $701(3.8 \%)$ \\
\hline Term (31-41 weeks) & $708(70.8 \%)$ & $12762(73.3 \%)$ & $13470(73.2 \%)$ \\
\hline Post-term ( $\geq 42$ weeks) & $66(6.6 \%)$ & $1209(6.9 \%)$ & $1275(6.9 \%)$ \\
\hline Missing & $2793(16.0 \%)$ & $173(17.3 \%)$ & $2966(16.1 \%)$ \\
\hline \multicolumn{4}{|l|}{ Small for gestational age, no. (\%) } \\
\hline Yes & $17(1.7 \%)$ & $141(0.8 \%)$ & $158(0.9 \%)$ \\
\hline No & $808(80.8 \%)$ & $14385(82.6 \%)$ & $15193(82.5 \%)$ \\
\hline Missing & $175(17.5 \%)$ & $2886(16.6 \%)$ & $3061(16.6 \%)$ \\
\hline \multicolumn{4}{|l|}{ Apgar score at 5 minutes after birth, no. (\%) } \\
\hline$<7$ & $6(0.6 \%)$ & $99(0.6 \%)$ & $105(0.6 \%)$ \\
\hline$\geq 7$ & $908(90.8 \%)$ & $16077(92.3 \%)$ & $16985(92.2 \%)$ \\
\hline Missing & $86(8.6 \%)$ & $1236(7.1 \%)$ & $1322(7.2 \%)$ \\
\hline \multicolumn{4}{|l|}{ Maternal age, $\mathrm{n}(\%)$} \\
\hline$\leq 20$ years & $100(10.0 \%)$ & $1638(9.4 \%)$ & $1738(9.4 \%)$ \\
\hline $21-35$ years & $852(85.2 \%)$ & $14794(84.9 \%)$ & $15646(84.9 \%)$ \\
\hline$>35$ years & $48(4.8 \%)$ & $980(5.6 \%)$ & $1028(5.6 \%)$ \\
\hline \multicolumn{4}{|l|}{ Mothers' marital status at subject's birth, $\mathrm{n}(\%)$} \\
\hline Married & $595(59.5 \%)$ & $11033(63.4 \%)$ & $11628(63.2 \%)$ \\
\hline Unmarried & $341(34.1 \%)$ & $5366(30.8 \%)$ & $5707(31 \%)$ \\
\hline Missing & $64(6.4 \%)$ & $1013(5.8 \%)$ & $1077(5.9 \%)$ \\
\hline \multicolumn{4}{|l|}{ Birth order, n (\%) } \\
\hline 1 & $320(32.0 \%)$ & $6063(34.8 \%)$ & $6383(34.7 \%)$ \\
\hline 2 & $368(36.8 \%)$ & $6148(35.3 \%)$ & $6516(35.4 \%)$ \\
\hline 3 & $183(18.3 \%)$ & $3173(18.2 \%)$ & $3356(18.2 \%)$ \\
\hline $4+$ & $129(12.9 \%)$ & $2026(11.6 \%)$ & $2155(11.7 \%)$ \\
\hline Missing & $0(0 \%)$ & $2(0.01 \%)$ & $2(0.01 \%)$ \\
\hline \multicolumn{4}{|l|}{ Mode of delivery, no. (\%) } \\
\hline Vaginal & $796(79.6 \%)$ & $14170(81.4 \%)$ & $14966(81.3 \%)$ \\
\hline Caesarean & 119 (11.9\%) & $1626(9.3 \%)$ & $1745(9.5 \%)$ \\
\hline Forceps or vacuum extraction & $85(8.5 \%)$ & $1616(9.3 \%)$ & $1701(9.2 \%)$ \\
\hline \multicolumn{4}{|l|}{ Hearing score at conscription, no. (\%) } \\
\hline Severe hearing impairment & $78(7.8 \%)$ & $754(4.3 \%)$ & $832(4.5 \%)$ \\
\hline Moderate hearing impairment & $274(27.4)$ & $3902(22.4 \%)$ & $4176(22.7 \%)$ \\
\hline No hearing impairment & $641(64.1 \%)$ & $12653(72.7 \%)$ & $13294(72.2 \%)$ \\
\hline Missing & 7 (0.7\%) & $103(0.6 \%)$ & 110 (0.6\%) \\
\hline
\end{tabular}

Among men without hearing impairment at the time of draft board evaluation, those who had been hospitalised with OM in early childhood had a $15 \%$ greater risk of a BPP score in the bottom quartile than the other men in the study (Table 2). Among men with severe hearing impairment $(7.9 \%$ of men with OM hospitalisation and
$4.4 \%$ of the men without), the proportions with a BPP score in the bottom quartile were similar $[\mathrm{PR}=1.01(95 \%$ CI: 0.78-1.34)].

Compared with men without childhood hospitalisation for OM, the adjusted PR for a BPP score in the bottom quartile for men with an $\mathrm{OM}$ hospitalisation was 1.20 


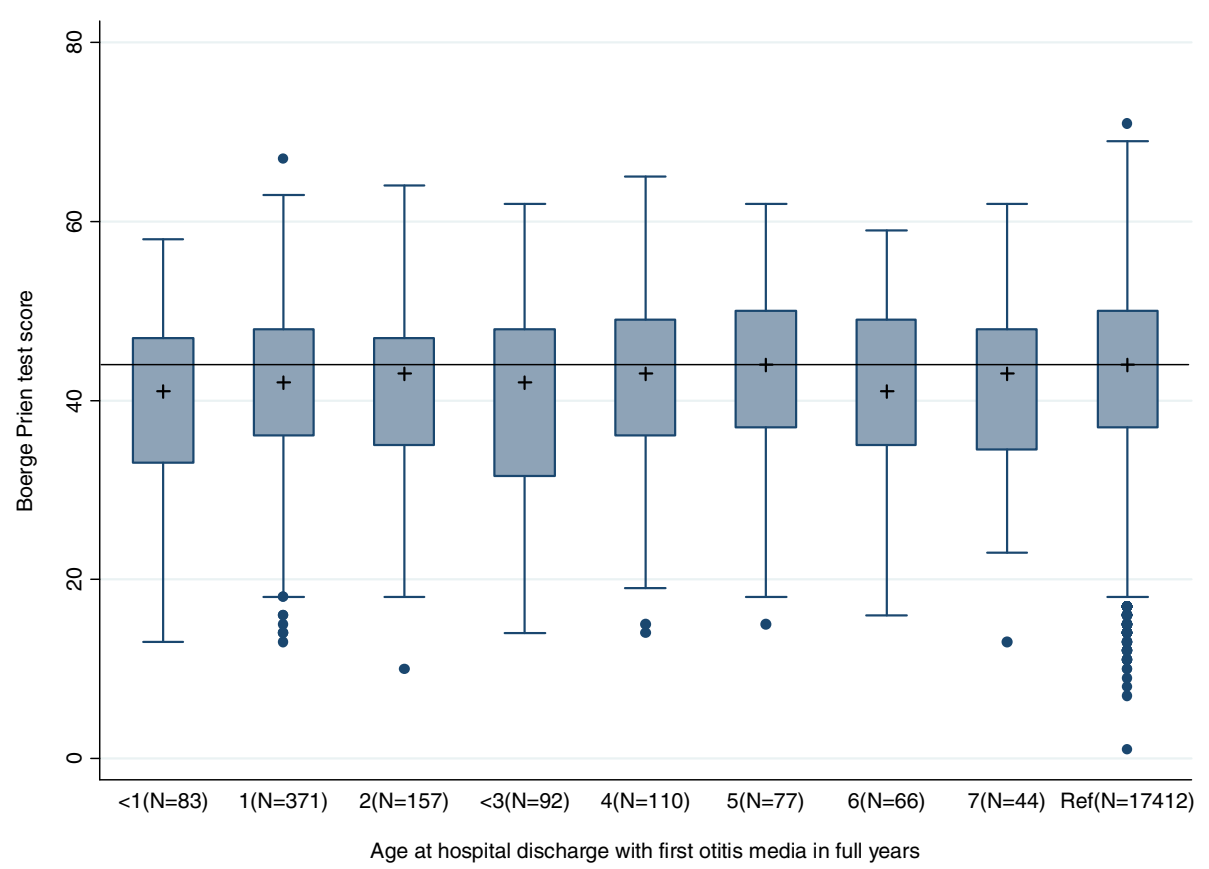

Figure 1 BPP scores by age at first hospitalisation diagnosis with otitis media (OM) in Danish conscripts. The group comprised conscripts without a hospitalisation with OM. The cross marks the median of a BPP score, and the box marks the upper and lower quartiles. The whiskers extend 1.5 times the interquartile range. Observations outside that range are plotted individually. The horizontal line shows sample median BPP, which equals 44.0 .

Table 2 Distribution of Boerge Prien test (BPP) scores and prevalence ratios, stratified according to hearing score

\begin{tabular}{|c|c|c|}
\hline & \multicolumn{2}{|c|}{$\begin{array}{l}\text { Otitis media hospitalisation } \\
\text { in childhood }\end{array}$} \\
\hline & Yes & No \\
\hline \multicolumn{3}{|l|}{$\begin{array}{l}\text { Severe hearing impairment } \\
\text { (hearing score } 0-3 \text { ) }\end{array}$} \\
\hline Number, \% & $78(7.9 \%)$ & $754(4.4 \%)$ \\
\hline Median BPP (quartile) & $40(32-47)$ & $39(33-46)$ \\
\hline Men with a BPP in the bottom quartile & $33(42.3 \%)$ & $313(41.5 \%)$ \\
\hline PR for BPP in the bottom quartile, $95 \% \mathrm{Cl}$ & $1.01(0.78-1.34)$ & 1 (reference) \\
\hline \multicolumn{3}{|l|}{$\begin{array}{l}\text { Moderate hearing impairment } \\
\text { (hearing score 4) }\end{array}$} \\
\hline Number, \% & $274(27.6 \%)$ & $3902(22.5 \%)$ \\
\hline Median BPP (quartile) & $41(33-46)$ & $43(38-49)$ \\
\hline Men with a BPP in the bottom quartile & $105(38.3 \%)$ & $1107(28.4 \%)$ \\
\hline PR for BPP in the bottom quartile, $95 \% \mathrm{Cl}$ & $1.35(1.15-1.58)$ & 1 (reference) \\
\hline \multicolumn{3}{|l|}{$\begin{array}{l}\text { No hearing impairment } \\
\text { (hearing score 5) }\end{array}$} \\
\hline Number, \% & $641(64.6 \%)$ & $12653(73.1 \%)$ \\
\hline Median BPP (quartile) & $43(38-49)$ & $44(38-50)$ \\
\hline Men with a BPP in the bottom quartile & $169(26.4 \%)$ & $2908(22.9 \%)$ \\
\hline PR for BPP in the bottom quartile, $95 \% \mathrm{Cl}$ & $1.15(1.01-1.32)$ & 1 (reference) \\
\hline Total & $993(100 \%)$ & 17309 (100\%) \\
\hline
\end{tabular}

(95\% CI: 1.09-1.33) (Table 3). None of the potential confounding variables noticeably affected the PR estimates, either separately or in combination. Including men who did not come to the conscription examination by imputing their BPP values did not changes the estimates.

There was no major variation in the prevalence of GCSE by quartiles of BPP scores among men with and without an OM hospitalisation in early childhood, as the PR was 0.89 (95\% CI: 0.59-1.33) for those in the bottom quartile of BPP scores and 0.96 (95\% CI: 0.88-1.05) for those in the upper quartile (Table 4). Excluding men who previously had been diagnosed with meningitis also did not change the estimates.

Assuming the worst case scenario, with all exempt men having a BPP score in the bottom quartile, resulted in a PR of 1.29 (95\% CI, 1.21 to 1.38$)$, while the surplus for the best case scenario was a PR of 1.09 (95\% CI, 0.99 to 1.21$)$.

\section{Discussion}

In this study of 18412 conscripts, we examined longterm cognitive outcomes after hospitalisation for OM before age 8 . Overall, we found that hospitalisation with OM in early childhood was associated with a slightly lower cognitive function in early adulthood except in 
Table 3 Crude and adjusted prevalence ratios for Boerge Prien test (BPP) scores overall and according to age

\begin{tabular}{|c|c|c|c|c|}
\hline & \multicolumn{2}{|c|}{ Total men with BPP score in the bottom quartile } & \multirow{2}{*}{\multicolumn{2}{|c|}{$\begin{array}{l}\text { PR for BPP score in the bottom quartile } \\
\mathrm{n}(\%)\end{array}$}} \\
\hline & & \multirow[t]{2}{*}{ n (\%) } & & \\
\hline & & & Crude PR & Adjusted* PR \\
\hline \multicolumn{5}{|c|}{ Hospitalisation with OM } \\
\hline No & 17412 & $4370(25.1)$ & 1 & 1 \\
\hline Yes & 1000 & $312(31.2)$ & $1.24(1.13-1.37)$ & $1.20(1.09-1.33)$ \\
\hline \multicolumn{5}{|c|}{ Age at first hospitalisation with OM } \\
\hline$<1$ year & 83 & $30(36.1)$ & $1.44(1.08-1.92)$ & $1.38(1.04-1.83)$ \\
\hline $1-2$ years & 528 & $163(31.0)$ & $1.23(1.07-1.40)$ & $1.17(1.03-1.33)$ \\
\hline $3-5$ years & 279 & $85(30.5)$ & $1.22(1.02-1.45)$ & $1.24(1.03-1.49)$ \\
\hline $6-7$ years & 110 & $34(30.9)$ & $1.23(0.93-1.63)$ & $1.17(0.89-1.54)$ \\
\hline
\end{tabular}

men with severe hearing impairment at the time of draft board evaluation. We found no association between hospitalisation for OM in early childhood and GCSE beyond that explained by level of cognitive function.

Our study thus extends the findings by Bennett et al. who found that some developmental sequelae of OME could continue into the early teens [10]. Our findings are in contrast to the studies of Roberts et al., Zumach et al., Grievink et al., and Johnson et al. [9,11-13] who could not detect any negative consequences of OM and OME by 7 years of age. However, these studies were all smaller than our population-based study. Additionally, our findings also agree with those of Welch and Dawes, which indicate that $\mathrm{OM}$ in early childhood does not affect the level of education attained [15].

We only focused on those admitted to the hospital for OM in early childhood. By age 3 it is estimated that $80 \%$ of all children have experienced at least one episode of OM [1], though only a minority of these children are admitted to the hospital. Admitted cases presumably represent more severe cases of OM. Still, other factors may influence whether or not a child is admitted to the hospital for OM, such as socioeconomic status (SES). Unfortunately, we had limited information on SES and were thus unable to determine whether our observed association could be explained by severity of $\mathrm{OM}$ or by other factors influencing hospitalisation for OM. In addition, hearing impairment is probably also related to the severity of OM [5]. Yet, when we stratified according to hearing impairment at conscription examination, we found no differences in BPP among men hospitalised for $\mathrm{OM}$ in early childhood. This could indicate that the correlation between OM and low BPP cannot be explained by hearing loss alone.

Our study has other strengths and limitations. The possibility of certain types of selection biases was reduced by independent collection of data on $\mathrm{OM}$ and BPP scores in a population with tax-funded free access to health care and free hospitalisations, if indicated. Still, we examined outcomes among men who survived and stayed in the region to conscription age, rather than following a birth cohort. We also lacked data on the cognitive function of men exempt from conscript examination; if some were exempt because of conditions related to $\mathrm{OM}$ and lower cognitive function, we may have underestimated the association between hospitalisation for $\mathrm{OM}$ and cognitive function in young adulthood [19]. However, imputing BPP scores for exempt men did not change our results. The sensitivity analysis showed that the risk of significant selection bias, because of the exempt men was minimal. In addition, our study relied on hospitalisation diagnoses, which may not have been

Table 4 Prevalence of GCSE among conscripts with and without hospitalisation for otitis media (OM), stratified by Boerge Prien test (BPP) scores

\begin{tabular}{|c|c|c|c|c|c|}
\hline & \multicolumn{2}{|l|}{ With GCSE } & \multicolumn{2}{|l|}{ Without GCSE } & \multirow[b]{2}{*}{ PR } \\
\hline & With OM n,\% & Without OM n,\% & With OM n,\% & Without OM n,\% & \\
\hline $\mathrm{BPP} \leq 37$ & $23(7.4)$ & $363(8.3)$ & $288(92.6)$ & $4000(91.7)$ & $0.89(0.59-1.33)$ \\
\hline BPP 38-44 & $89(28.7)$ & $1481(31.2)$ & $221(71.3)$ & $3272(68.8)$ & $0.92(0.77-1.10)$ \\
\hline BPP 45-50 & $104(52.8)$ & $2389(55)$ & $93(47.2)$ & $1954(45)$ & $0.96(0.84-1.10)$ \\
\hline $\mathrm{BPP}>50$ & $134(74.0)$ & $3022(76.9)$ & $47(26)$ & $906(23.1)$ & $0.96(0.88-1.05)$ \\
\hline Total & \multicolumn{2}{|c|}{7605 (41.4) } & \multicolumn{2}{|c|}{$10781(58.6)$} & \\
\hline
\end{tabular}


accurately registered [27]. Misclassification of the OM diagnosis could have biased our relative estimates toward the null. Moreover, we were able to control for several gestational factors, but we lacked information on variables related to maternal lifestyle, such as smoking, alcohol intake, and medication use. We also lacked information on the home environment, day-care attendance, and further social factors of the conscripts as children, all of which may be potential confounding factors [10,28-31]. Although adjustment for measured confounders led to only minor changes in our estimates, unmeasured confounding can not be excluded as a potential explanation for the associations found in this study.

\section{Conclusion}

Overall, we found a slightly lower cognitive function in early adulthood among men who were hospitalised with $\mathrm{OM}$ in early childhood. Further, we found no association between hospitalisation with OM and GCSE when the level of BPP was taken into account.

\section{Endnote}

${ }^{\mathrm{a}}$ General Certificate of Secondary Education: is referring to the Danish Upper Secondary School Leaving Examination.

\section{Abbreviations}

BPP: Boerge Prien test (Danish Børge Prien Prøve); DNRP: Danish National Registry of Patients; GCSE: General Certificate of Secondary Education ${ }^{\text {a }}$; ICD: International Classification of Diseases; PR: Prevalence ratio; OM: Otitis media; OME: Otitis media with effusion; SES: Socioeconomic status; WAIS: Wechsler Adult Intelligence Scale.

\section{Competing interests}

The authors declare that they have no competing interests and no financial relations to disclose that are relevant to this article.

\section{Authors' contributions}

$\mathrm{MM}, \mathrm{RBN}, \mathrm{NF}$, and MN contributed to the conception and design of the study. MM, RBN, and MN contributed to the analysis of the data. All authors contributed to the interpretation of the data, drafting or revising of the manuscript, and final approval for publication. MM and MN are the guarantors.

\section{Acknowledgements}

The study received financial support from the Clinical Epidemiological Research Foundation.

\section{Author details}

${ }^{1}$ Department of Clinical Epidemiology, Aarhus University Hospital, Olof Palmes Allé 43-45, 8200, Aarhus N, Denmark. ${ }^{2}$ H.C. Andersen Children's Hospital, Odense University Hospital, Sdr. Boulevard 29, 5000, Odense C, Denmark.

Received: 6 July 2012 Accepted: 11 January 2013

Published: 15 January 2013

\section{References}

1. Teele DW, Klein JO, Rosner B: Epidemiology of otitis media during the first seven years of life in children in greater Boston: a prospective, cohort study. J Infect Dis 1989, 160(1):83-94.

2. Rovers MM: The burden of otitis media. Vaccine 2008, 26(Suppl 7):G2-G4.
3. Hansen MP, Jarbol DE, Gahrn-Hansen B, Depont Christensen R, Munck A, Ellegaard Trankjaer Ryborg C, et al: Treatment of acute otitis media in general practice: quality variations across countries. Fam Pract 2012, 29(1):63-68.

4. Roberts JE, Burchinal MR, Zeisel SA: Otitis media in early childhood in relation to children's school-age language and academic skills. Pediatrics 2002, 110(4):696-706.

5. Monasta L, Ronfani L, Marchetti F, Montico M, Vecchi Brumatti L, Bavcar A, Grasso D, Barbiero C, Tamburlini G: Burden of disease caused by otitis media: systematic review and global estimates. PLoS One 2012, 7(4):e36226.

6. Gravel JS, Wallace IF, Ruben RJ: Auditory consequences of early mild hearing loss associated with otitis media. Acta Otolaryngol 1996, 116(2):219-221.

7. Colletti L, Mandala M, Zoccante L, Shannon RV, Colletti V: Infants versus older children fitted with cochlear implants: performance over 10 years. Int J Pediatr Otorhinolaryngol 2011, 75(4):504-509.

8. Carney AE, Moeller MP: Treatment efficacy: hearing loss in children. J Speech Lang Hear Res 1998, 41(1):S61-S84.

9. Roberts JE, Rosenfeld RM, Zeisel SA: Otitis media and speech and language: a meta-analysis of prospective studies. Pediatrics 2004, 113(3 Pt 1):e238-e248.

10. Bennett KE, Haggard MP, Silva PA, Stewart IA: Behaviour and developmental effects of otitis media with effusion into the teens. Arch Dis Child 2001, 85(2):91-95.

11. Zumach A, Gerrits E, Chenault M, Anteunis L: Long-term effects of early-life otitis media on language development. J Speech Lang Hear Res 2010, 53(1):34-43.

12. Grievink EH, Peters SA, van Bon WH, Schilder AG: The effects of early bilateral otitis media with effusion on language ability: a prospective cohort study. J Speech Hear Res 1993, 36(5):1004-1012.

13. Johnson DL, Swank PR, Owen MJ, Baldwin CD, Howie VM, McCormick DP: Effects of early middle ear effusion on child intelligence at three, five, and seven years of age. J Pediatr Psychol 2000, 25(1):5-13.

14. Paradise JL, Dollaghan CA, Campbell TF, Feldman HM, Bernard BS, Colborn DK, Rockette HE, Janosky JE, Pitcairn DL, Sabo DL, Kurs-Lasky M, Smith CG: Language, speech sound production, and cognition in three-year-old children in relation to otitis media in their first three years of life. Pediatrics 2000, 105(5):1119-1130.

15. Welch D, Dawes P: No negative outcomes of childhood middle ear disease in adulthood. Laryngoscope 2007, 117(3):466-469.

16. Lynge E, Sandegaard JL, Rebolj M: The Danish National Patient Register. Scand J Public Health 2011, 39(7 Suppl):30-33.

17. Frank L: Epidemiology, When an entire country is a cohort. Science 2000, 287(5462):2398-2399.

18. Kjøller M, Rasmussen NK: Danish Health and Morbidity Survey 2000. . \& trends since 1987. Denmark, Copenhagen: National Institute of Public Health; 2002.

19. Mortensen EL, Reinisch M, Teasdale TW: Intelligence as measured by the WAIS and military draft board group test. Scand J Psychol 1990, 31:315.

20. Knudsen LB, Olsen J: The Danish Medical Birth Registry. Dan Med Bull 1998, 45(3):320-323.

21. Military conscription board: Annex to the military conscription board's circular of 1 July 1985 of the procedures for conscription examination etc. Denmark, Copenhagen; 1985.

22. McNutt LA, Wu C, Xue X, Hafner JP: Estimating the relative risk in cohort studies and clinical trials of common outcomes. Am J Epidemiol 2003, 157(10):940-943.

23. Marsal K, Persson PH, Larsen T, Lilja H, Selbing A, Sultan B: Intrauterine growth curves based on ultrasonically estimated foetal weights. Acta Paediatr 1996, 85(7):843-848.

24. Schafer L: Joseph: Analysis of incomplete multivariate data. New York: Kluwer Academic Publishers Group; 1997.

25. Klebanoff MA, Cole SR: Use of multiple imputation in the epidemiologic literature. Am J Epidemiol 2008, 168(4):355-357.

26. Ehrenstein V, Pedersen L, Grijota M, Nielsen GL, Rothman KJ, Sorensen HT: Association of Apgar score at five minutes with long-term neurologic disability and cognitive function in a prevalence study of Danish conscripts. BMC Pregnancy Childbirth 2009, 9:14.

27. Green J, Wintfeld N: How accurate are hospital discharge data for evaluating effectiveness of care? Med Care 1993, 31(8):719-731.

28. Kerschner EJ: Chapter 639- Otitis Media. In Textbook of Pediatrics. 18th edition. Philadelphia: SAUNDERS ELSEVIER; 2007. 
29. Mortensen EL, Andresen J, Kruuse E, Sanders SA, Reinisch JM: IQ stability: the relation between child and young adult intelligence test scores in low-birthweight samples. Scand J Psychol 2003, 44(4):395-398.

30. Engel J, Anteunis L, Volovics A, Hendriks J, Marres E: Prevalence rates of otitis media with effusion from 0 to 2 years of age: healthy-born versus high-risk-born infants. Int J Pediatr Otorhinolaryngol 1999, 47(3):243-251.

31. Wolke D, Schmid G, Schreier A, Meyer R: Crying and feeding problems in infancy and cognitive outcome in preschool children born at risk: a prospective population study. J Dev Behav Pediatr 2009, 30(3):226-238.

doi:10.1186/1471-2431-13-8

Cite this article as: Mortensen et al: Hospitalisation with otitis media in early childhood and cognitive function in young adult life: a prevalence study among Danish conscripts. BMC Pediatrics 2013 13:8.

\section{Submit your next manuscript to BioMed Central and take full advantage of:}

- Convenient online submission

- Thorough peer review

- No space constraints or color figure charges

- Immediate publication on acceptance

- Inclusion in PubMed, CAS, Scopus and Google Scholar

- Research which is freely available for redistribution 